\title{
Configurações
}

Revista de sociologia

\section{O malogro da beleza, ou uma incapacitação crítica da homonormatividade}

The failure of beauty, or: a critical incapacitation of homonormativity

L'échec de la beauté, ou: l'incapacité critique de l'homonormativité

\section{António Fernando Cascais}

\section{OpenEdition}

\section{Journals}

Edição electrónica

URL: http://journals.openedition.org/configuracoes/2639

DOI: $10.4000 /$ configuracoes.2639

ISSN: 2182-7419

\section{Editora}

Centro de Investigação em Ciências Sociais

Edição impressa

Data de publição: 30 Junho 2015

Paginação: 71-83

ISBN: 1646-5075

ISSN: 1646-5075

\section{Refêrencia eletrónica}

António Fernando Cascais, « O malogro da beleza, ou uma incapacitação crítica

da homonormatividade », Configurações [Online], 15 | 2015, posto online no dia 01 setembro 2015 consultado o 19 abril 2019. URL : http://journals.openedition.org/configuracoes/2639; DOI : 10.4000/ configuracoes. 2639

Este documento foi criado de forma automática no dia 19 Abril 2019.

(c) CICS 


\section{O malogro da beleza, ou uma incapacitação crítica da homonormatividade}

The failure of beauty, or: a critical incapacitation of homonormativity

L'échec de la beauté, ou: l'incapacité critique de l'homonormativité

\section{António Fernando Cascais}

"Vê, enfim, que ninguém ama o que deve,

Senão o que somente mal deseja"

Os Lusíadas, Canto IX, 29

\section{O modelo estético-erótico}

Se continua a ser verdade, como sempre foi, que "quem o feio ama, belo lhe parece", nem por isso o dito popular exclui - bem pelo contrário - o facto de o olhar amoroso, longe de ser uma pura e espontânea resposta ao estímulo de alguma beleza intrínseca ou essencial ao objeto amado que assim o afetaria, antes projeta sobre este um arquétipo estruturante e formativo que lhe permite percebê-lo como belo. Este pressuposto de base - que a beleza está no olhar de quem a vê - é determinante para percebermos, nas suas implicações pertinentes para o propósito deste texto, um parâmetro estético-erótico de beleza/ juventude que se encontra identificado, pelo menos desde que Michael Pollak (1982) o incluiu como elemento constitutivo do "habitus homossexual". Pollak inspira-se em Pierre Bourdieu (2002: 163), que defi ne habitus como um "sistema de disposições duradouras" que "designa (...) uma maneira de ser, um estado habitual (em especial do corpo) e, em particular, uma predisposição, uma tendência, uma propensão ou uma inclinação" para ser e para fazer que é "resultado de uma ação organizadora" (Ibidem), e que, "produto de uma aquisição histórica, é aquilo que permite a apropriação da aquisição histórica" (Bourdieu, 1998: 133). Bourdieu mostra assim que o corpo é espaço de mediação (Ibidem: 138) ou de "interiorização da exterioridade" e "exteriorização da interioridade" 
(Bourdieu, 2002: 163), "quer dizer, a incorporação das estruturas sociais sob a forma de estruturas disposicionais" (Bourdieu, 1998: 114). Nesta conformidade, Pollak definia o “ habitus homossexual" como aquilo que guia o modo de vida e "resulta da socialização anterior ao coming out e do grau de interiorização das regras do meio [gay]" (Pollak, 1982: 41). Com o tempo entretanto decorrido, o modelo estético-erótico referido por Pollak só se viria a tornar ainda mais reconhecível, disseminado e atuante nos meios gay, além de ter extravasado largamente as fronteiras culturais e sociais das comunidades gay para se expandir no imaginário social exterior a elas, nomeadamente por via do contributo capital que deu ao esbater das fronteiras que opunham homoerotismo e heteroerotismo no plano dos modelos de identificação masculina.

5 A traço grosso, trata-se do "esquema corporal" (Bourdieu, 2010: 329) do homem que não é simplesmente jovem e belo, mas hipersaturado de sinais de juventude e de beleza como hexis corporal (Bourdieu, 1999: 55) duplamente estética - isto é, de aparência física e pose corporal, ou de "charme e carisma" (Bourdieu, 2010: 317) - e erótica - isto é, de sedução e atração sexual - e que, por sua vez, funcionam como interpretantes peircianos de muitos outros signos relativos a outros domínios de valor (de género, profissional, económico, psicossocial, cultural, ético, etc.), que não apenas o estético e o erótico. Além disso, estes sinais encontram-se frequentemente associados àquilo que a língua inglesa tem consagrado com o termo de attitude, o qual comporta um desempenho e uma fachada na interação simbólica interindividual, tal como foram definidos por Erving Goffman (1993: 29-48), ou, por outras palavras: uma postura, e uma postura que convoca a segurança autoafirmativa, a assertividade, a ostensividade e a agressividade cinésica, a interação dramatúrgica que explora os aspetos cénicos da apresentação de si e os consequentes efeitos de sideração provocados nos observadores. Por intermédio dessa attitude, o modelo estético-erótico potencia a equação dos valores de beleza e de juventude com uma masculinidade pujante e luminosa, que cultiva uma aura hetero (straight-looking), com o êxito profissional (ocupação de prestígio, competitividade, produtividade) e com o sucesso económico dele decorrente (níveis elevados de rendimento e de consumo), com a integração psicossocial (elevada autoestima, felicidade, superabundância e qualidade de solicitações e relacionamentos sociais) e com o valor pessoal (iniciativa, independência, excelência, competência). Este modelo estético-erótico, que tem sido mais questão de identificação empírica do que objeto de caracterização e análise reflexiva formal e erudita, é por vezes valorizado como modelo de identificação positiva para os jovens gay como "fórmula geradora de habitus" (Bourdieu, 2010: 317), acabando desse modo por se insinuar de forma determinante nos processos de subjetivação operantes na illusio (Bourdieu, 1998: 119, 133, 146) do jogo de integração dos jovens no meio gay. Entende-se a noção de illusio aqui aplicada como "a maneira de ser dentro do mundo, de ser ocupado pelo mundo que faz com que o agente possa ser afetado por uma coisa muito afastada ou até mesmo ausente, mas participando no jogo com que ele se encontra cometido" (Ibidem: 119) e que, constituindo assim o campo social como jogo, "é o que faz com que os pensamentos e as ações possam ser afetados e modificados fora de qualquer contacto físico e até mesmo de qualquer interação simbólica, em particular na e pela relação de compreensão" (Ibidem). Mas isto sabemo-lo desde há muito: a beleza pode ser muda, mas o certo é que pictura loquens, facto notório na atual ascensão do manequim (de resto, quer feminino, quer masculino) como modelo de referência. Acontece que o privilégio atribuído à eloquência imagética, ao mesmo tempo que exacerba a pulsão escópica de longas tradições na cultura ocidental, potencia o cuidado da imagem como competência 
comunicacional e a imagem cuidada como indicador de proficiência do desempenho dotado de valor axiológico (Bourdieu, 1999: 55) e que só não constitui uma marca da distinção social porque na verdade consubstancia aquilo que Bourdieu (2010: 332) justamente mostrou ser um "elitismo do pobre".

Nesta medida, impõe-se igualmente reparar, ainda que em simples nota, que o modelo estético-erótico de beleza/juventude não é herdeiro, nem sequer se apresenta como uma anamorfose, do dandismo e do esteticismo dos tempos de Baudelaire e Wilde - embora seja inteiramente plausível que conserva, mas muito transformados, alguns dos seus avatares (o desigualitarismo wildiano, a tirania do dandismo baudelairiano) -, nem de modo algum se apresenta também como expressão da sensibilidade estética exacerbada que uma conceção essencialista atribuía à homossexualidade - pelo que neste aspeto mantém igualmente uma ambígua afinidade com o programa desnaturalizador dos esteticismos baudelairiano e wildiano, pois tanto para estes como para o modelo estéticoerótico a beleza é uma questão de estilização ou de estilo de vida.

Resta acrescentar que este modelo estético-erótico é assiduamente veiculado pela publicidade e pelas publicações especializadas no segmento masculino do público, como notaram estudos tanto internacionais como nacionais (Bourdieu, 2010: 309-339; Januário e Cascais, 2012), alguns dos quais com forte componente de investigação empírica, em cujas conclusões baseámos o presente texto (Januário, 2009, 2013; Veríssimo, 2008). Sintomaticamente mas que não deverá surpreender - veiculam-no tanto as publicações claramente dirigidas a públicos gay, como as publicações que nunca se afirmam vocacionadas para esse público-alvo, facto que se deixa denunciar pela invariável ausência de menção à homossexualidade e o evitamento escrupuloso de conotação com a masculinidade gay nelas, mas que são igualmente consumidas por esse público. Tanto configura o modelo estético-erótico como ponto de convergência das masculinidades homo e hetero (Ponce, 2009: 276), mas que, ao contrário de infirmar o seu carácter homonormativo, realmente o corrobora, facto que é consentâneo com uma observação de Raewyn Connell e James Messerschmidt (2005: 839): “É extremamente provável que haja um certo grau de sobreposição ou de interpenetração entre masculinidades hegemónicas e coniventes se a hegemonia é eficaz." Essa sobreposição, acrescentam, é igualmente visível quanto aos agentes sociais que constroem a masculinidade, o que se aplica ao que anteriormente afirmámos no que respeita ao idêntico papel desempenhado tanto por publicações dirigidas a públicos gay como a outro(s) público(s). Eis também porque comungam do mesmo erro de avaliação as ideias populares de que este fenómeno atesta o grau de integração social da comunidade gay (expresso no cliché de que o gay está na moda), ou, opostamente, de que ele comprova a ameaça dissolvente de uma homossexualização da sociedade (expresso num pânico social homossexual). Por este mesmo motivo, partilhamos da desconfiança de Connell e Messerschmidt (2005: 845) quanto ao facto de a hibridização se ter tornado globalmente hegemónica (embora com admissíveis exceções locais). Na verdade, estamos perante uma das consequências maiores de uma transformação social mais vasta da masculinidade (Connell, 1995, 1998, 2000) como ser-percebido - que dantes definia em exclusivo o feminino (Bourdieu, 1999: 54-59) -, a qual, sem dúvida, é de molde a levantar suspeitas acerca do carácter intercambiável da distinção entre homonormatividade e heteronormatividade enquanto normatividades masculinas, como se esclarecerá adiante. De resto, estas mesmas suspeitas foram já levantadas por Connell e Messerschmidt (2005: 841) noutro contexto, mas com idêntico sentido: "Os homens podem ziguezaguear entre múltiplos sentidos de acordo 
com as suas necessidades interacionais. Os homens podem adotar a masculinidade hegemónica quando tal é desejável; mas os mesmos homens podem distanciar-se estrategicamente da masculinidade hegemónica noutros momentos. Consequentemente, a 'masculinidade' não representa um certo tipo de homem, mas, antes, uma maneira de os homens se posicionarem a si próprios por meio de práticas discursivas." E não só por meio de práticas discursivas, mas igualmente por meio de práticas não discursivas, como é o caso das práticas (moda, desporto, imagem publicitária, etc.) pertinentes ao âmbito deste texto, o qual, por outro lado, incorpora também, como deverá ser evidente, a revisão do conceito de masculinidade hegemónica, empreendida pela própria pessoa de Connel, que inicialmente o desenvolveu, e que doravante inclui a ideia de uma diversidade, de uma pluralidade e inclusive de uma hierarquia dinâmica de masculinidades hegemónicas e subordinadas (Ibidem: 845).

8 Não está nas intenções da presente abordagem privilegiar o carácter compensatório deste modelo estético-erótico, que, em todo o caso, nos parece indesmentível no plano dos seus reais usos e efeitos comunicacionais. Com efeito, se o entendermos como busca de reconhecimento equivocada e autodestrutiva que em última análise se alimenta da acumulação de um capital simbólico, ele pode reproduzir a ambiguidade que é constitutiva do capital simbólico tal como o descreveu Bourdieu (1998: 147), porquanto comporta o "princípio de uma busca egoísta das satisfações do 'amor-próprio' que é simultaneamente perseguição fascinada da aprovação de outrem". Mesmo assim, não é difícil, de forma breve e sumária, fazer corresponder a cada projeção sublimada, típica daquele modelo, outros tantos estereótipos, tão devastadores e insidiosos quanto difundidos, que desfiguram o homossexual naqueles mesmíssimos planos de valor (de género, profissional, económico, psicossocial, cultural, ético, etc.) onde ele o sublima: afetado, efeminado, de masculinidade frustre distorcida por inúmeros maneirismos imediatamente reconhecíveis, inepto a não ser em ocupações mais feminis do que varonis, ou então vocacionado para atividades profissionais de sentido equívoco ou questionável e valor ambíguo, figura histriónica e exibicionista mais do que realmente competente e fiável, com proventos incertos e flutuantes, socialmente isolado e inadaptado, senão mesmo marginal, fisicamente frágil e psicologicamente instável, dependente, inconstante e suscetível em extremo, emocionalmente volúvel e influenciável, o que por sua vez se reflete numa conduta eticamente comprometida pela passividade, o oportunismo calculista, a pusilanimidade, a duplicidade, a futilidade e a gratuitidade, a imprevidência e a irresponsabilidade aditiva e hedonista. Ana Maria Brandão (2010: 111) lembra muito justamente, a este respeito, que

A presença da culpa liga-se ao facto de a não conformidade do portador do estigma poder ser lida não só como um sinal da sua diferença, mas, sobretudo, de uma inferioridade moral, no sentido lato do termo, pela qual se é visto e se vê como responsável. $\mathrm{O}$ homo-erotismo é um estigma que faz recair sobre o actor o anátema da falha de carácter, da vontade fraca, da submissão a paixões tirânicas ou 'não naturais'. (...) Além de ser olhado como portador de um estigma, o indivíduo é, ainda, considerado responsável pela sua posse e, como estas crenças foram por ele incorporadas, ele tende a assumir como verdadeiras as atribuições que lhe são endereçadas.

9 Mais, é inteiramente admissível que a correlação entre, por um lado, beleza e juventude e, por outro, saúde e felicidade, dissimule a insistência, omitida, recalcada, inconfessada e enfim fantasmática, dos efeitos últimos da patologização médico-científica e da estigmatização social que se agravou exponencialmente com a epidemia de sida e que continuam a manter muito do peso que sempre tiveram na deterioração identitária dos 
homens gay. A recorrência desta deterioração da identidade, sob a forma de matériaprima de vergonha (e a ser trabalhada enquanto "vergonhosa"), é inegável nos próprios processos de reconstituição reparadora da subjetividade por cujo intermédio o homossexual estigmatizado se transforma em gay assumido e afirmativo. Tudo isto também conhecemos bem. Na verdade, aquela possível correlação aponta para algo de bem mais profundo e que se pode reconhecer de forma menos especulativa, que é o facto de o modelo estético-erótico de beleza/juventude não poder prescindir, na sua própria definição, de um sistema de oposições binárias que o sustentam, porventura bem mais do que a necessidade percebida, e o propósito mais ou menos consciente e deliberado de compensar a estereotipização negativa do homem gay, que sempre foi contraposta à diferenciação da "masculinidade como nobreza" (Bourdieu, 1999: 49-54). Trata-se de um sistema de oposições sociossexuadas homólogas com eixo nos binarismos belo/feio e jovem/velho, necessariamente hierárquicos e não simétricos, e que de algum modo repercutem o valor ritual da oposição arcaica entre o limpo e o sujo, além de consubstanciarem o proverbial geracionismo (ageism) das relações gay, que por sua vez constitui uma modalidade muito agravada do geracionismo masculino hetero. Desses binarismos axiais pode-se derivar um repertório inteiro de outros, tais como visível/ invisível, desejável/repulsivo, nobre/vil, louvável/repreensível, admirável/desprezível, imponente/ridículo, promissor/decadente, triunfador/falhado, sublime/abjeto, aprimorado/degradado, emblemático/inapresentável, integrado/excluído, exaltado/ desqualificado, emulável/evitável, orgulhoso/vergonhoso... e enfim: heterossexual/ homossexual (Ibidem: 90). Há um inevitável preço a pagar pela forma como o modelo estético-erótico mobiliza os atributos do polo positivo daquelas oposições hierárquicas, que consiste em remeter para uma incompatibilidade de essência com os atributos dele toda e qualquer (sugestão de, e por ínfima que seja) possível homossexualidade: a ideia é que todo aquele que se possa vincular aos atributos positivos deste sistema de oposições deixa de aparentar a homossexualidade estereotipada das representações populares. Por outras palavras: se é homossexual, em nada e por nada parece sê-lo.

10 Tenhamos agora em conta, a este propósito, os adquiridos das reflexões antropológicoculturais e psicossociológicas. Elas dizem-nos, nomeadamente: que o corpo é suporte de valores sociais (Le Breton, 2000: 86-91); que existe um laço indissolúvel entre a aparência e a apresentação moral, desde que a Antiguidade clássica correlacionou beleza e virtude ( Ibidem: 97-99); que os "jogos da aparência inscrevem-se num vasto sistema simbólico cujos efeitos sociais estão longe de ser negligenciáveis" (Maffesoli, 1993: 136). Tanto assim é que se pode falar de um verdadeiro "narcisismo de grupo" (Ibidem: 151), cujo eixo da identificação deve ser encontrado do lado das "modulações do corpo em espetáculos [que] simbolizam o corpo social" (Ibidem: 142) e fundam assim a dialética corpo próprio/corpo social. Os adquiridos das reflexões antropológico-culturais e psicossociológicas dizemnos, enfim, que a exploração narcísica do capital libidinal individual (Lipovetsky, 1989: 29-30) é tão individualizadora quanto coletivizadora, pois o Egobuilding, enquanto produção narcísica (Ibidem: 131), acaba por cumprir uma função normalizadora do corpo (Le Breton, 1989: 108).

11 Nesta conformidade, não é descabido interpretar o modelo estético-erótico, por outro lado celebrativo e eufórico, em dois sentidos:

12 a) como sintoma de luto por uma masculinidade heterossexual e heteronormativa intimamente inatingível; ou seja: o trauma fundador que eternamente retorna com a suspeita de que o straight-looking não passa de expediente compensador que se implanta 
protesicamente sobre uma falta originária, ou uma defi ciência, ou uma carência, um aleijão constitutivo (o não ser completamente homem...) e o concomitante pânico do fracasso no cumprimento integral, "com felicidade" (Bourdieu, 1998: 126), dos protocolos da masculinidade; $\mathrm{e}$

b) como reativação do investimento que põe em marcha a máquina virilizadora totalmente identificada com os parâmetros identitários heteronormativos.

Embora este modelo seja frequentemente derrogado como "nazi", impõe-se obviar à trivialização do totalitarismo que tal derrogação acarreta. Nem por isso ele deixa de ser portador de algumas analogias funestas com a biopolítica nazi. Ainda que não de uma forma historicamente literal, trata-se de um modelo eugenista que procede pela seleção entre indivíduos incluídos e indivíduos excluídos, uma máquina seletora inteiramente dissociada de qualquer lógica emancipatória, que não só estigmatiza quantos nem sequer sejam candidatos a incorporar o padrão, como rejeita os seus próprios produtos falhados ou desatualizados. Reinstala a vergonha (já de si decorrente da objetificação heteronormativa do homossexual) e amplia-lhe os efeitos identitários, lá mesmo de onde expulsa o orgulho (que, ao invés de um imaginário de "morte aos feios", é inclusivo: "se ele foi capaz de..., então eu também posso ser"). Precipita o sentimento de inadaptação e desestima própria a quem se faz saber, por todas as formas não verbais, que "não presta", ao mesmo tempo que o expõe ao medo do contágio da vergonha, pois quem é vergonhoso, além de sentir vergonha, envergonha os outros. Lembra Brandão (2010: 111) que, se o sentimento de vergonha é fortemente perturbador, é precisamente porque não tem apenas uma origem externa, mas resulta de normas e valores incorporados. E observa Eve Kosofky Sedgwick (2003: 36-37) que a vergonha é a afeção que mais define o espaço no interior do qual o sentido do eu se irá desenvolver, o lugar onde a questão da identidade irrompe da forma mais original e mais relacional:

Com efeito, a vergonha e a identidade mantêm uma relação muito dinâmica uma com a outra, ao mesmo tempo desestruturante e fundacional, porque a vergonha é tão peculiarmente contagiosa como peculiarmente individualizadora. Um dos traços mais estranhos da vergonha (...) é a maneira como o mau tratamento de outrem, o mau tratamento por outrem, o embaraço, o estigma, a fragilidade, o mau cheiro, ou o comportamento estranho de outrem, nada tendo que ver comigo aparentemente, pode inundar-me tão prontamente (...) com aquela sensação cuja ubiquidade parece delinear os meus precisos limites individuais da maneira mais isoladora que imaginar se possa.

Além de eugenista, o modelo é melhorista. Realmente, o que a seleção eugénica visa é o melhorismo, visto que não se limita a opor e hierarquizar traços desejáveis e indesejáveis, antes avança daí para distinguir entre indivíduos suscetíveis de aperfeiçoamento e indivíduos "irrecuperáveis" ou "incorrigíveis", a saber, quantos sejam tidos como fracassos no processo de experimentação de melhoramentos ou então que correspondam a fases anteriores dele e tidas como ultrapassadas e desatualizadas relativamente a aperfeiçoamentos mais recentes. Significa isto que o modelo inclui uma vertente de expurgo (a exclusão e, senão a eliminação, pelo menos a invisibilização dos elementos irrecuperáveis), paralela ao apuramento melhorador (betterment) por meio da intensificação (enhancement) de traços desejáveis (exemplo paradigmático: a massa muscular). Na verdade, encontramo-nos perante um autêntico trabalho de Sísifo autoproliferante (que desencadeia automaticamente a sua própria ultrapassagem) e autofágico (que devora as suas etapas ultrapassadas). Longe de realizar a normalidade como mediana estatística com vocação para se universalizar, ele transforma-a em móbil 
inalcançável sempre em vias de se devorar a si próprio, incumprindo-se no impulso da sua realização e que mobiliza uma produtividade paroxística necessariamente geradora de subprodutos disfuncionais como o burnout, a vigorexia, o investimento narcísico autoabsorvente e obsessivo com efeitos antissociais (Lipovetsky, 1989: 102-104). Muitíssimo longe de recuperar de algum modo o ideal olímpico grego (com o qual por vezes também é popularmente confundido) devidamente enquadrado na competição corpo a corpo da paideia clássica, a qual, aliás, também compreendia a sua própria forma de eugenismo, o atual modelo melhorista impõe um outro tipo de competição na era tecnocientífica: tal como nas olimpíadas modernas em que o atleta compete com uma marca ou uma medida (tempo, altura, comprimento...) que medeia o confronto corpo a corpo e no qual a montra do cronómetro substitui as feições humanas do rosto do semelhante-adversário, trata-se doravante de competir, nem bem consigo próprio, mas contra si próprio, para superar cada meta atingida que se apresenta sempre como nova limitação (pois nunca se consegue ser suficientemente definido, simétrico, etc., a partir do momento em que o índice de massa gorda ou a ingestão de calorias são mensuráveis), e cada limitação tem o mesmo efeito sísmico que uma ínfima borbulha. Em função do seu carácter eugenista-melhorista, pode-se pois definir o modelo estético-erótico como um modelo ortogenético assente na mobilização biopolítica de uma produtividade indefinida autoproliferante, autofágica e, em derradeira instância, autodestrutiva.

Ora, o que guia o nosso raciocínio não é de modo nenhum fazer a apologia de um malditismo inassimilável, e que em regra se verte em formas de intervenção política alimentadas pelo puro ressentimento desprovido de verdadeiras alternativas, mas antes a valorização de um pensamento gay-lésbico originalmente crítico, a cuja luz o modelo estético-erótico procede ao apagamento das marcas históricas, tanto de uma herança de opressões, como dos próprios combates políticos e culturais que sedimentam toda a possível definição do que pode ser uma "vida boa" ou "vida ética" no termo de uma história LGBTQ de maneira nenhuma redutível a uma assunção estética.

\section{O malogro da beleza}

O que a este propósito havia de fundacional para ser dito disse-o Sedgwick (2003: 61): "a 'performatividade queer' é o nome de uma estratégia para a produção de sentido e de ser, relativamente à afeção da vergonha e ao posterior facto do estigma que com ela está relacionado." Mais: a vergonha é politicamente interessante "porque gera e legitima o lugar da identidade - a questão da identidade - na origem do impulso para o performativo, mas fá-lo sem elevar o espaço dessa identidade ao estatuto de uma essência. Constitui-o como para-ser-constituído, que é o mesmo que dizer já aí para a (necessária, produtiva) desconstrução e desidentificação" (Ibidem: 63). Uma vez dada por adquirida esta natureza mediadora da vergonha, e ressalvando-se que o lugar da identidade que é delineado pela vergonha não basta para estabilizar a consistência interna dessa identidade, a qual pode ainda ser, e muitas vezes é mesmo, determinada ainda por fatores de raça, género, classe, sexualidade, aparência e perfeição física, pode do mesmo modo reconhecer-se que

As formas que toma a vergonha não são partes 'tóxicas' isoladas da identidade de um grupo ou de um indivíduo passíveis de serem dele excisadas; são, ao invés, integrais aos processos pelos quais a própria identidade se forma, bem como seus excedentes. Elas encontram-se disponíveis para o trabalho de metamorfose, redefinição, refiguração, transfiguração, carga e deformação simbólica e afetiva, 
mas talvez sejam demasiado potentes para o trabalho de expurgo e término deontológico. (Ibidem)

18 Ao assegurar ainda que as particulares estruturas de expressão, de criatividade, de prazer e de luta derivam dessa afeção originária, Sedgwick aponta para o papel determinante por elas desempenhado na metamorfose ou na reconversão da vergonha em orgulho, no caso das identidades deterioradas.

Alguns contributos podem ser de imprescindível utilidade para aparelhar aquilo que gostaríamos de chamar uma incapacitação crítica dos efeitos homonormativos do modelo estético-erótico de beleza/juventude. Antes de mais, impõe-se reconhecer que a dominância e a autoridade social dele, que não uma real hegemonia a que faltam condições suficientes que permitam perfazê-la, se encontram eficazmente limitadas pelo crescimento de identidades que definitivamente não se regem por parâmetros eugenistas e melhoristas, tais como, e tão-só a título de exemplo, as comunidades dos "ursos", BDSM, leather, girth and mirth, transgénero e transsexual, bem como a comunidade lésbica inteira que sempre foi fortemente refratária a qualquer infl uência do modelo geracionista gay. A sua simples existência deve constituir um óbice à pretensão de representarem de forma universalizante a diversidade intrínseca das comunidades LGBTQ, ou, se assim quisermos, das "multitudes queer" (Preciado, 2003: 24), exclusivamente através das imagens uniformizadoramente "apresentáveis" do modelo estético-erótico, ao preço da anulação de todos os affreux que são delas excluídos. Genericamente, pode dizer-se que estes grupos se encontram nas melhores condições para desenvolver práticas de desidentificação, as quais se traduzem por outras tantas estratégias de sobrevivência que lhes permitem resistir a modelos de identificação socialmente prescritivos que têm por efeito a homogeneização e a assimilação de identidades queer, mas que, na mesma base teóricopolítica, podem ser aplicadas às forças homonormativas atuantes no interior das comunidades gay sempre que elas têm idêntico efeito homogeneizador e assimilador, como pode ser o caso do modelo estético-erótico. Não está aqui sequer em causa a relativa invulnerabilidade de grupos como estes aos efeitos homogeneizadores do modelo estético-erótico, em virtude das próprias características de cada um, nem da sustentação de qualquer separatismo com base na respetiva naturalização a partir delas. No caso das mulheres lésbicas, nem sequer é legítimo falar de um "grupo" no sentido em que pode ser aceitável aplicá-lo aos demais. Embora também se possa falar a seu respeito de um determinado modelo estético-erótico, que aponta mormente para a femme e que tem sido denunciado por algumas autoras especialmente atentas e críticas (Halberstam, 2011: 94-96), ele não reúne as características bastantes, nem a intensidade dos respetivos efeitos, para poder ser encarado como equivalente ao que opera para os homens gay. De maneira exclusivamente parentética, poderíamos observar que, a termos de procurar tal equivalente, mais depressa o detetaríamos a funcionar para as mulheres hetero, o que nos levaria a um outro mundo de considerações incomportáveis no presente texto. Nada terá, pois, de acaso a concentração da reflexão de Judith (Jack) Halberstam (2011: 96-105) sobre a arte queer do malogro (the queer art of failure) na figura da lésbica butch. Entre os raríssimos textos que abordam este preciso tema, Brandão situa-o nos termos mais exatos. Após reparar que embora a butch - a "camionista" na sua tradução lusa - seja fonte de desconforto e embaraço para as demais lésbicas que com ela não se identificam (Brandão, 2010: 168-169), basicamente porque tendem a resistir à sua redução a um tipo pelo facto de ela acarretar estigmatização, diz:

Ora, a aparência física das mulheres é altamente valorizada, em particular como

factor de atração sexual, razão pela qual ela tem sido apontada como menos 
importante para as lésbicas (...). Neste sentido, um estilo menos (ou não) conforme aos padrões da feminilidade hegemónica pode ser visto como uma consequência, simultaneamente, da sua menor preponderância em termos de atração sexual e do desejo de reduzir ou afastar tentativas de sedução por parte dos homens. (Ibidem: 170)

Por seu lado, Halberstam (2011: 95) esclarece que, no caso das lésbicas, a "camionista" tende a ser retratada como o estereótipo não só da lésbica caricatural, mas da perdedora, feia e má, em permanente luto de uma feminilidade bem-sucedida, ao passo que as mulheres femmes se prestam ao aproveitamento pelo imaginário heteropornográfico e se transformam em produto de consumo, visto que a mercantilização, enquanto processo, depende por inteiro de expectativas visuais e eróticas heteronormativas. Acontece que, do ponto de vista de um programa crítico-político do malogro queer, e como já bem tinha assinalado Brandão, a estratégia de perturbação do género desenvolvida pela "camionista" pode ser encarada como expediente eficaz de dissuasão do assédio masculino. 0 malogro tem, pois, de se localizar no seio do leque de afeções políticas que chamamos queer (Halberstam, 2011: 89), e podemos concluir que ele intervém por intermédio da incapacitação crítica da homonormatividade, visto que contribui decisivamente para limitar os efeitos do modelo estético-erótico ao torná-lo basicamente inoperante. Nesta conformidade, o malogro do estereótipo da beleza feminina pela "camionista", ao contrário de poder ser legitimamente representado como falta de resistência, tem de ser reconhecido como uma das armas do arsenal dos fracos que pode ser usada para recategorizar a relação entre pessoas do mesmo historicamente marcada pela sua associação com o fracasso, a perda e a impossibilidade, enquanto as relações heterossexuais assentam numa lógica de completude, realização e sucesso (Ibidem: 94) e, por essa via, como uma forma de recusar a aquiescência com as lógicas dominantes do poder e da disciplina: "A arte queer do malogro põe em jogo o impossível, o improvável, o imprevisível e o irrelevante. Perde discretamente e ao perder imagina outras finalidades para a vida, para o amor, para a arte e para o ser" (Ibidem: 88).

\section{BIBLIOGRAFIA}

BOURDIEU, Pierre (2010), A Distinção: Uma crítica social da faculdade de juízo. Lisboa: Edições 70.

BOURDIEU, Pierre (2002), Esboço de uma Teoria da Prática. Oeiras: Celta.

BOURDIEU, Pierre (1999), A Dominação Masculina. Oeiras: Celta.

BOURDIEU, Pierre (1998), Meditações Pascalianas. Oeiras: Celta.

BRANDÃo, Ana Maria (2010), E se Tu Fosses um Rapaz? Homo-erotismo feminino e construção social da identidade. Porto: Edições Afrontamento.

CONNELL, Raewin W. (1998), Gender \& Power. Stanford: Stanford University Press.

CONNELL, Raewin W. (1995), Masculinities. Berkeley: University of California Press.

CONNELL, Raewin W. (2002), Gender. Cambridge: Polity Press. 
CONNELL, Raewin W.,MESSERSCHMIDT, James W. (2005), “Hegemonic Masculinity: Rethinking the concept", Gender and Society, 19: 829-859.

GOFFMAN, Erving (1993), A Apresentação de Si na Vida de todos os Dias. Lisboa: Relógio d'Água.

HALBERSTAM, Judith (2011), The Queer Art of Failure. Durham and London: Duke University Press.

JANUÁRIO, Soraia Bernardino Barreto (2013), Género e Media: Estereótipos das masculinidades na publicidade das revistas masculinas em Portugal, Tese de Doutoramento em Ciências da Comunicação, especialidade de Comunicação e Cultura, Faculdade de Ciências Sociais e Humanas da Universidade Nova de Lisboa [em linha], disponível em http://run.unl.pt/handle/10362/10957 [consultado em: 10 de março de 2015].

JANUÁRIO, Soraia Bernardino Barreto (2009), As Masculinidades Contemporâneas e a sua Representação nos Media: As revistas de estilo de vida masculina Men's Health com edição em Portugal e no Brasil, Tese de Mestrado em Ciências da Comunicação, Variante de Estudos dos Media e Jornalismo, Faculdade de Ciências Sociais e Humanas da Universidade Nova de Lisboa [em linha], disponível em http://www.bocc.ubi.pt/pag/januario-soraya-as-masculinidadescontemporaneas.pdf [consultado em: 10 de março de 2015].

JANUÁRIO, Soraia Bernardino Barreto, CASCAIS, António (2012), “O corpo masculino na publicidade: Uma discussão contemporânea”, Revista Comunicação e Sociedade, 21: 135-148.

LE BRETON, David (2000), La Sociologie du corps. Paris: PUF.

LIPOVETSKY, Gilles (2004), o Crepúsculo do Dever. Lisboa: Dom Quixote.

LIPOVETSKY, Gilles (1989), A Era do Vazio. Lisboa: Relógio d’Água.

MAFFESOLI, Michel (1993), Au creux des apparences: Pour une éthique de l'esthétique. Paris: Plon.

POLLAK, Michael (1982), "L'homosexualité masculine, ou: le bonheur dans le ghetto", Communications, 35: 37-55.

PONCE, Adriana Fuentes (2009), "El discurso sobre la estética del cuerpo de los hombres", in J. C. Rodríguez e G. U. Vásquez (coords.), Masculinidades: El juego de género de los hombres en el que participan las mujeres, Madrid: Plaza y Valdés: 269-282.

PRECIADO, Beatriz (2003), “Multitudes Queer: Notes pour une politique des 'anormaux”, Multitudes, 12: 17-25.

SEDGWICK, Eve Kosofsky (2003), Touching Feeling: Affect, pedagogy, performativity. Durham and London: Duke University Press.

VERÍSSIMO, Jorge (2008), O Corpo na Publicidade. Lisboa: Edições Colibri.

\section{RESUMOS}

O habitus homossexual comporta um parâmetro estético-erótico de beleza/juventude de carácter geracionista, eugenista e melhorista, mais compensatório do que verdadeiramente emancipatório da vergonha fundacional da identidade homossexual. Frequentemente apresentado como modelo de identificação para os jovens gay, ele tem profundos efeitos homonormativos nos processos de subjetivação gay. Um uso produtivamente político da performatividade queer combate os estragos devastadores deste modelo no próprio seio dos processos de subjetivação gay com recurso aos contributos da arte queer do malogro. 
The homosexual habitus comprises an aesthetico-erotic parameter of beauty/youth that is ageist, eugenicist and melioristic in nature, and which is compensational rather than emancipatory regarding the foundational shame of the homosexual identity. Often presented as an identifi cation model for gay youths, it has profound homonormative effects in the gay subjectification processes. A productively political use of queer performativity counters the devastating ravages of this model at the very heart of the gay subjectification processes by resorting to the critical powers of the queer art of failure.

L'habitus homosexuel comporte un paramètre esthético-erótique de beauté/jeunesse ayant un caractère âgiste, eugéniste et meilleuriste, davantage compensatoire qu'émancipatoire en ce qui concerne la honte promotrice de l'identité homosexuelle. Fréquemment présenté comme modèle d'identification pour les jeunes gays, il a de profonds effets homonormatifs sur les processus de subjectivation gay. Un usage productivement politique de la performativité queer combat les dégâts dévastateurs causés par ce modèle au sein même des processus de subjectivation gay euxmêmes par moyen de l'art queer de l'échec.

\section{ÍNDICE}

Mots-clés: esthético-érotique; échec; honte; homonormativité; performativité queer. Keywords: aesthetic-erotic; failure; shame; homonormativity; queer performativity Palavras-chave: estético-erótico, malogro, vergonha, homonormatividade, performatividade queer

\section{AUTOR}

\section{ANTÓNIO FERNANDO CASCAIS}

Prof. Auxiliar na Faculdade de Ciências Sociais e Humanas da Universidade Nova de Lisboa.

Endereço

de correspondência: UNL/FCSH, Av. de Berna, 26-C, 1069-061 Lisboa

afcascais@netcabo.pt 